\title{
Importance of long-term monitoring for detecting environmental change: lessons from a lowland river in south east England
}

\author{
T. P. Burt ${ }^{1}$, N. J. K. Howden ${ }^{2}$, F. Worrall ${ }^{3}$, and M. J. Whelan ${ }^{2}$ \\ ${ }^{1}$ Department of Geography, Durham University, Durham DH1 3LE, UK \\ ${ }^{2}$ Department of Natural Resources, Cranfield University, Cranfield, Bedfordshire MK43 0AL, UK \\ ${ }^{3}$ Department of Earth Sciences, Durham University, Durham DH1 3LE, UK
}

Received: 20 May 2008 - Published in Biogeosciences Discuss.: 6 June 2008

Revised: 27 August 2008 - Accepted: 10 September 2008 - Published: 11 November 2008

\begin{abstract}
Rising nitrate concentrations in rivers and groundwater in regions with intensive agriculture have been of concern for several decades. Long records of nitrate concentration are rare; in the UK, few pre-date 1974. Records from the River Stour from 1937 are analysed using moving-windows to explore the effects of window width on trend detection and process inference. Nitrate concentrations rose sharply from the late 1950s in response to widespread ploughing of grassland, but have fallen since the early 1980s, suggesting that widespread nitrogen control measures, which were introduced after the start of the downward trend, may not be the principal driver for recent change. Short windows (5 years) are too noisy; longer windows (10, 15 and 30 years) identify signals (i.e. trends) more reliably. Since system response times can be of the order of 20-30 years, management decisions made on shorter data sets (even up to 15 years) could be misleading.
\end{abstract}

\section{Introduction}

High nitrate concentrations in rivers and groundwater have been a matter of concern throughout the developed world for several decades (Burt et al., 1993). Initially, the main concern was about human health, reflected in the European Drinking Water Directive (EU 80/778). More recently, legislation, viz the European Nitrates Directive (91/676/EEC), has included reference to nitrate's role in eutrophication (including coastal waters where primary productivity is likely to be nitrogen-limited). Since the 1970s, a clear link has been established between agricultural activity and nitrate transfer from land to surface and ground water (Royal Society, 1983). Of the nitrogen which enters surface waters in Eng-

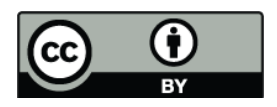

Correspondence to: T. P. Burt (t.p.burt@durham.ac.uk) land and Wales, $61 \%$ estimated to originate from agricultural land and 32\% from sewage effluent (Hunt et al., 2004), although these proportions will vary in different catchments. In rural catchments, nitrate losses from farmland predominate (>90\%: Casey et al., 1993). The designation of Nitrate Vulnerable Zones in the Nitrates Directive demonstrated that protective action was considered to be a feasible alternative to water treatment as a remedy. However, at the catchment scale, solute transfers are often characterised by considerable delays in response times (Owens and Edwards, 1992; Kirchner et al., 2000) so detection of water quality improvements resulting from NVZ designation is usually impossible in the short term.

Studies of temporal variation in nitrate concentration in relation to changing climate and land use have focused on single river basins (Casey and Clarke, 1979; José, 1989; Worrall and Burt, 1999) or combined records from many catchments to make regional comparisons (Roberts and Marsh, 1987; Betton et al., 1991; Stuart et al., 2007). For example, an upward trend in nitrate concentrations was reported for the period 1971-1985 at Slapton Wood, a small catchment of mixed land use in Devon, UK (Burt et al., 1988). Agricultural intensification within the catchment (including ploughing of grassland, increased ploughing frequency, higher fertiliser application rates, introduction of new crops, higher stocking densities) is most likely to account for the upward trend (Burt and Johnes, 1997). After accounting for the trend, nitrate concentration was shown to be controlled by antecedent rather than concurrent conditions. A "memory effect" (Burt et al., 1988) was evident with dry years followed by higher concentrations than expected in subsequent years and vice versa. Recent analysis (1971-2005) showed that the upward trend had not continued and that the "memory effect" had reversed in sign, suggesting change from supply- to transportlimited controls on nitrate leaching (Burt and Worrall, 2007). There have been many studies of nitrate trends, but unless analysis spans many years, short-term fluctuations caused by

Published by Copernicus Publications on behalf of the European Geosciences Union. 

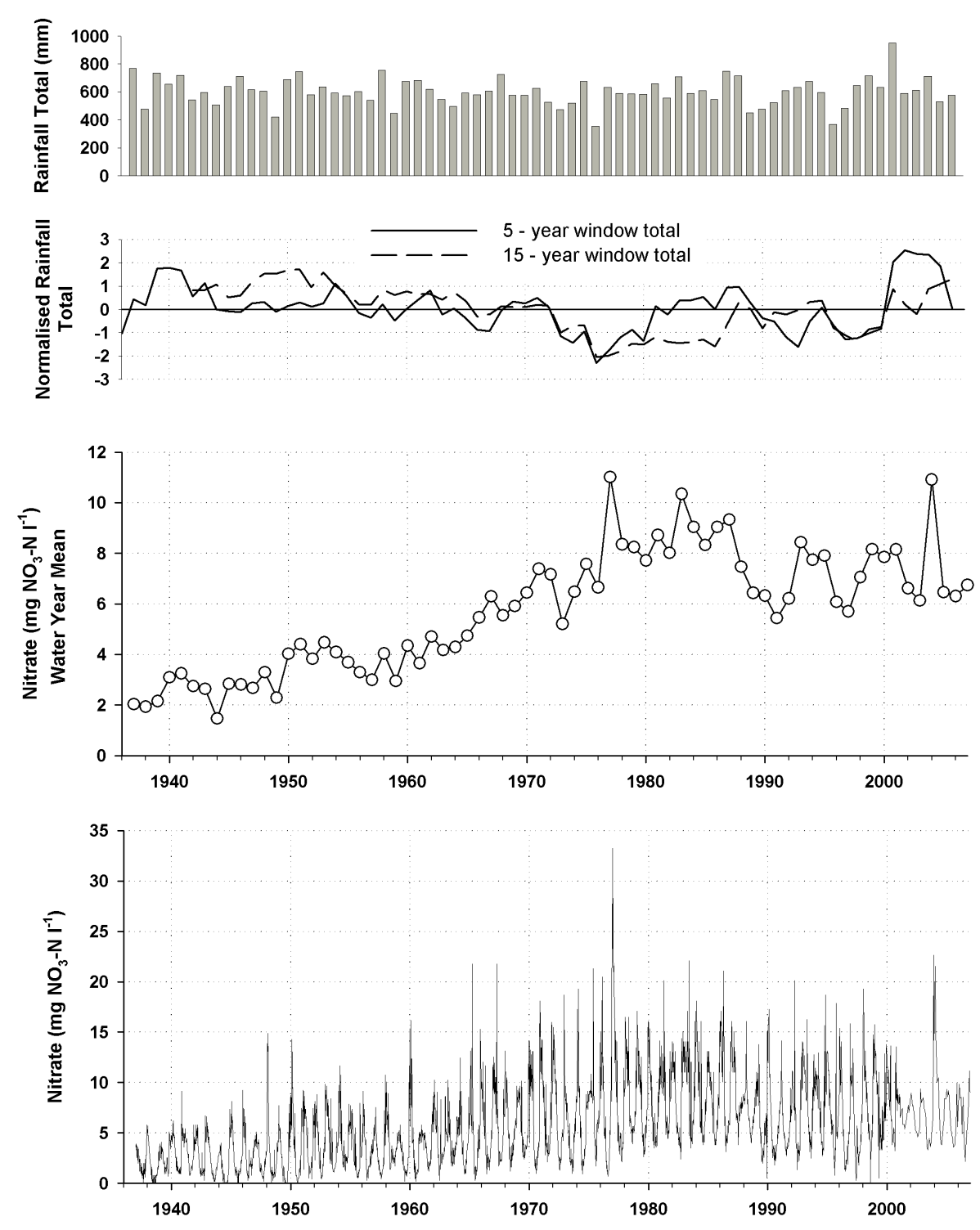

Fig. 1. The time series of nitrate concentrations for the River Stour since 1937. The bottom graph shows the raw data series. The middle graph shows the annual mean concentrations. The upper graphs show annual rainfall totals (mm) and normalised totals for 5- and 15-year windows. All data for water years beginning 1 October. All nitrate concentrations in $\mathrm{mg} \mathrm{NO}_{3}-\mathrm{Nl}^{-1}$.

climatic variations may be misinterpreted as trends. For example, a recent report that $77 \%$ of c. 6000 surface water sites in England had a declining nitrate concentration (ADAS, 2006) must be viewed with caution since only five years' data were employed and very few "trends" were statistically significant. The same criticism can be levelled at an earlier study (Betton et al., 1991) which used similarly short windows. This interest in long-term trends in nitrate concentrations matches recent interest in long-term hydrological trends, for example in rainfall (e.g. Burt and Horton, 2007) and streamflow (e.g. Dixon et al., 2006).

\section{Analyses}

The Environment Agency of England and Wales provided nitrate records for the River Stour at Langham Bridge (Station Number 036006; National Grid Reference 62 TM 020 344; Lat: $51^{\circ} 58^{\prime} 16.85^{\prime \prime}$, Long: $0^{\circ} 56^{\prime} 21.75^{\prime \prime}$ ): weekly data for 1937-2001; thereafter monthly samples. These data have previously been discussed by Roberts and Marsh (1987). Whilst there are no details of the sampling or analytical methodologies available, the data series does not exhibit any characteristics that suggest that results have been affected by changes in analytical procedures. The only significant change is the alteration in sampling frequency 
(a) 5-year window
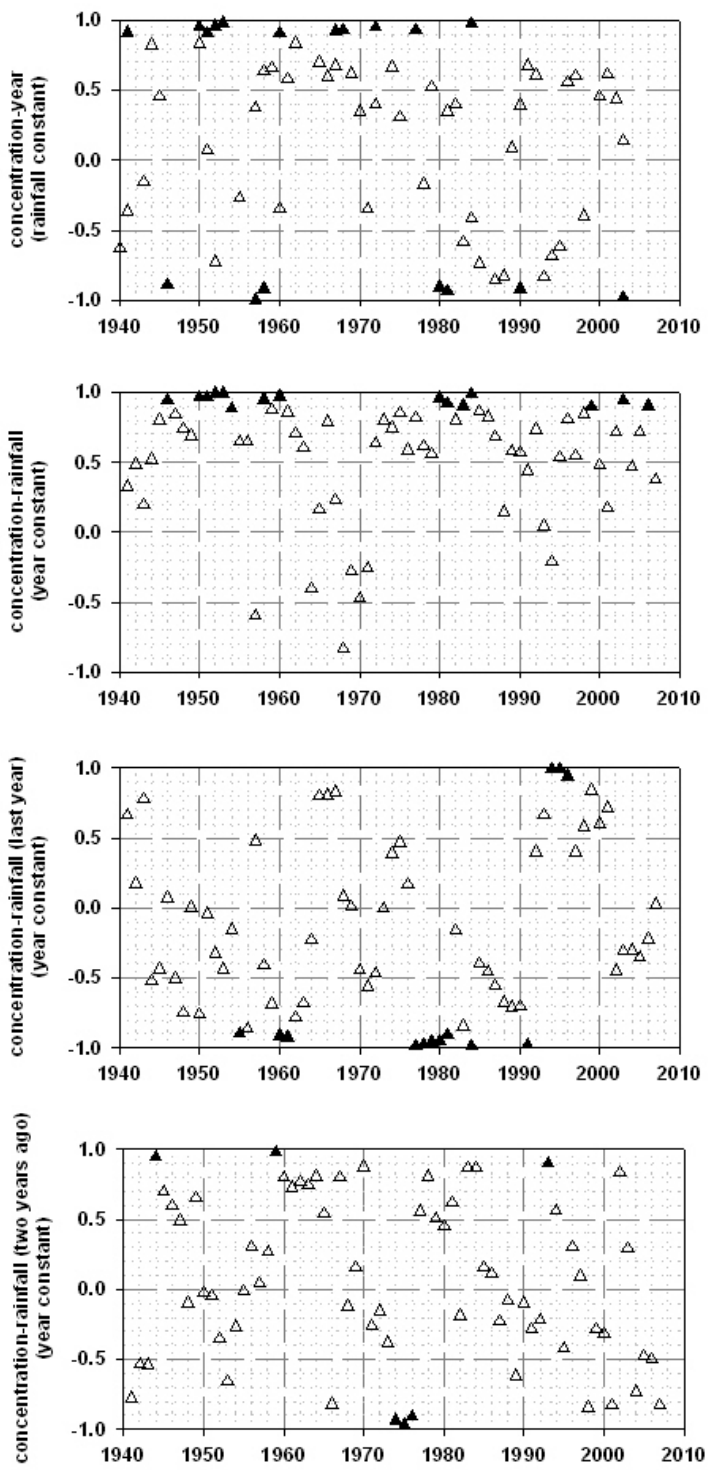

(b) 10-year window
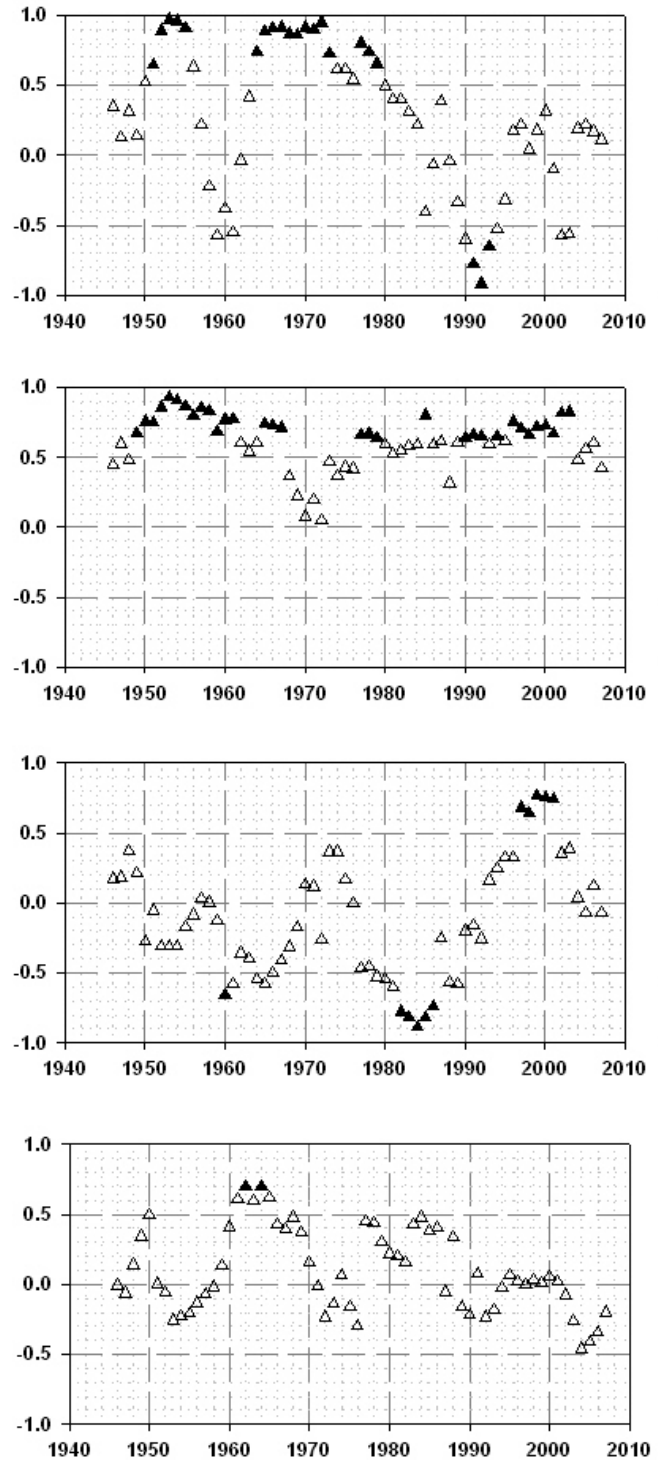

Fig. 2. Moving window partial correlation results for 5, 10, 15 and 30-year windows. The independent variables are (from top to bottom): year, rainfall in current water year (rf), rainfall in previous water year ( $\mathrm{rf}-1)$, and rainfall two years ago (rf-2). Solid and open symbols represent significant $(p<0.05)$ and non-significant correlations respectively.

from approximately weekly to monthly in 2001. The National River Flow Archive provided catchment rainfall totals (Fig. 1). We have used rainfall data instead of flow data because it is equally relevant as a climatic driver and, unlike the flow record, there is a complete record to match the nitrate series. The catchment $\left(578 \mathrm{~km}^{2}\right)$ is low-lying $(7-128 \mathrm{~m}$ a.s.l.) and dominated by arable land $(76 \%$ arable, $13 \%$ grassland, 4\% urban: National River Flow Archive (2008)). Annual mean nitrate-nitrogen concentrations $\left(\mathrm{mg} \mathrm{NO}_{3}-\mathrm{Nl}^{-1}\right)$ and rainfall totals were calculated for water years beginning 1 October; water years are more appropriate than calendar years because this fits better with the annual hydrological cycle of river discharge. All the data used have been supplied by national agencies, each of which employs their own quality assurance procedures.

Figure 2 presents partial correlations between annual mean nitrate concentration and independent variables: year number (Anno Domini); annual rainfall total in the current year (rf); annual rainfall total lagged by one year ( $\mathrm{rf}-1)$; and, annual rainfall total lagged by two years ( $\mathrm{rf}-2)$. A partial correlation coefficient indicates correlation between a dependent variable and one independent variable whist holding constant 
(c) 15-year window
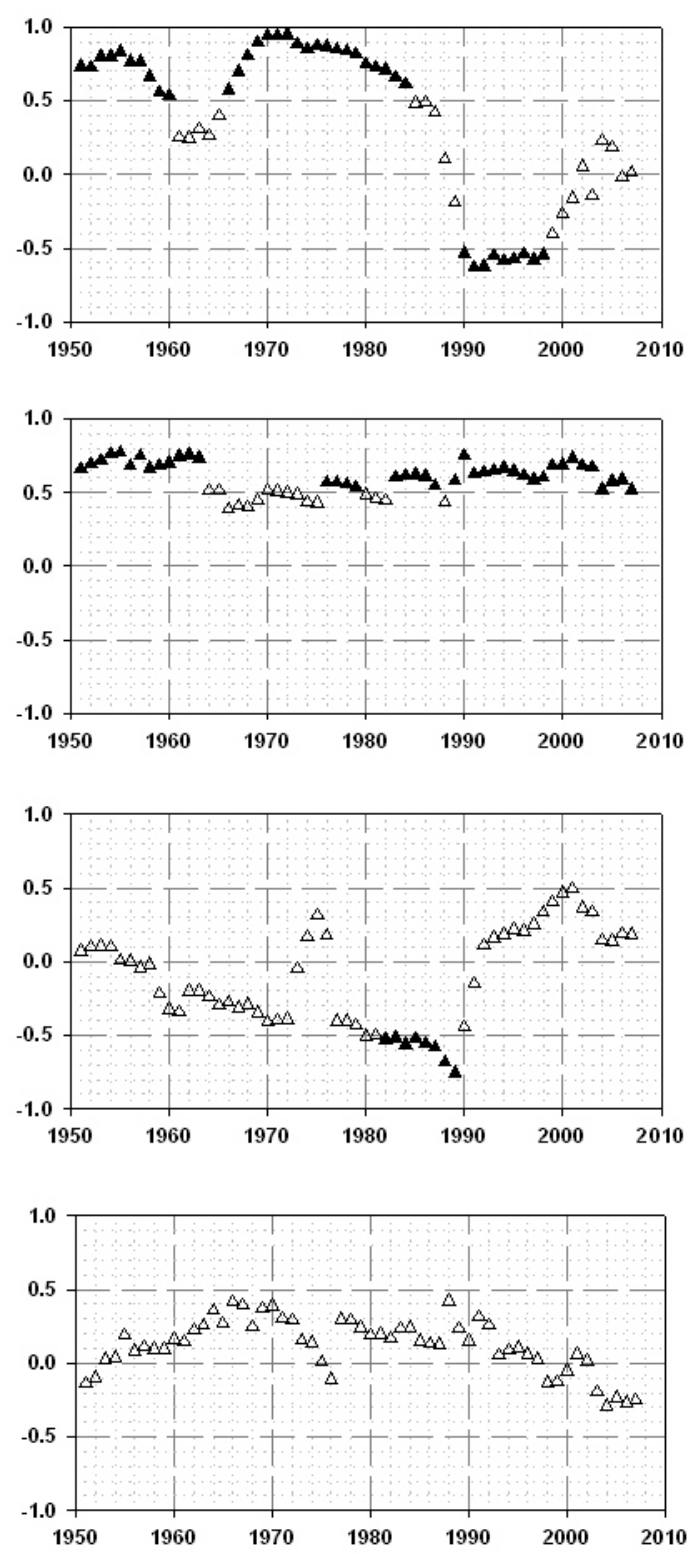

(d) 30-year window
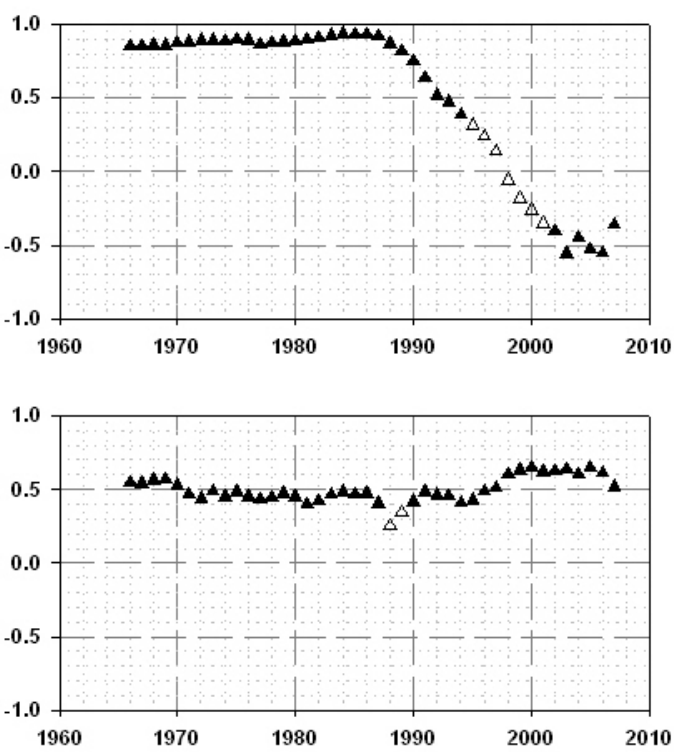

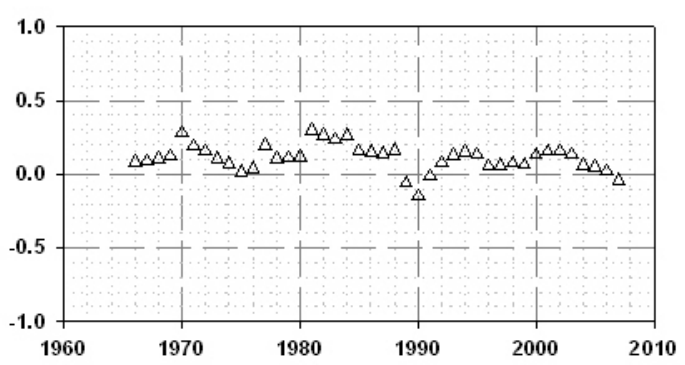

Fig. 2. Continued.

effects of other specified independent variables (Johnston, 1987). Here, we consider the effect of year, independent of rainfall, and vice versa. Correlations are repeated using a "moving window" analysis (Worrall et al., 2003) with the result plotted against the final year of the series. This was done using a custom-built MATLAB ${ }^{\mathrm{TM}}$ (The Mathworks Inc, Natick, Massachusetts) routine. Consistent trends can be identified from patterns of consecutive significant correlations. Correlations are deemed significant if the probability of chance occurrence is less than 5\%. Moving windows of $5,10,15$ and 30 years are used to demonstrate the effect of window width on trend identification and the role of climatic controls at varying time scales. The purpose here is to examine the effect of "window width" on the parametric testing commonly used to identify statistically significant "trends" (i.e. Pearson's correlation coefficient). In this respect, the focus here is not the actual trend, but the way in which the presence of "trend" is evaluated. A non-parametric equivalent (e.g. Mann-Kendall) was not considered, as this would not be appropriate for investigating either the temporal nitrate trend or the "memory effect". Further, the parametric test allows partial correlations to be calculated. 


\section{Results}

A seasonal cycle is evident in the raw data with maxima in late winter and minima in late summer (Fig. 1). A long upward trend begins in the late 1950s (average rate of increase: $0.22 \mathrm{mg} \mathrm{NO}_{3}-\mathrm{N}^{-1}$ ), peaking in the mid 1980s, after which concentrations gradually decline (average rate of decrease: $0.05 \mathrm{mg} \mathrm{NO}_{3}-\mathrm{N}^{-1}$ ). As for most rivers in southern England, conspicuously high concentrations follow the severe 1975-1976 drought (Doornkamp et al., 1978). The annual series shows that lower concentrations are often associated with drier years in the 1990s. The higher concentrations that follow occur in wetter years, probably due to the flushing of excess nitrate from the system.

There is great inconsistency between successive 5-year windows (Fig. 2a). Depending on when a period starts, it is possible to get very different trends. There are some statistically significant trends, positive and negative, but overall the record is noisy with no clear signal. Rainfall is highly variable in short records; correlations with rf are mainly positive as expected but with many non-significant results. Correlations with $\mathrm{rf}-1$ are mainly negative when significant, implying exhaustion effects as described above, but there are three significant positive results in the dry period of the early 1990s. There are only six significant correlations with $\mathrm{rf}-2$, three positive and three negative, but these do not suggest any consistent "memory effect".

Ten-year windows show longer periods of significant upward trend but there are significant downward trends ending in the early 1990s (Fig. 2b); the influence of high concentrations in the mid-1980s is crucial. Correlations with rf are all positive including many significant results; correlations are weaker in the early 1970 s, which was a very dry period. Correlations with $\mathrm{rf}-1$ shift from mainly negative in windows ending in the mid 1980s to positive in the late 1990s. This mirrors findings elsewhere (e.g. Betton et al., 1991) and reflects high rainfall in this period. For $\mathrm{rf}-2$, two correlations are significantly positive in the early 1960 s and gradually become negative, but not significant.

Results from 15-year windows immediately indicate coherent patterns of change (Fig. 2c). Long-term trends are positive and mostly significant through to the mid 1980s. Trends then switch (over just five windows) to become significantly negative through the 1990s. Correlations with rf are consistently positive and significant, except for windows ending 1964-1975. Patterns observed with 10-year windows are, therefore, confirmed when longer records are used. For correlations with $\mathrm{rf}-1$, there is one period of significant negative correlations for windows ending in the 1980s, again matching what was seen using 10-year windows. There is no pattern with correlations for $\mathrm{rf}-2$ : all are non-significant.

Thirty-year windows show a very smooth pattern of change (Fig. 2d). Even so, strong positive trends identified by windows ending in the late 1980s are followed by a relatively rapid change with trends for the last 6 windows be- ing significantly negative. High concentrations in the period 1977-1986 exert key influence over observed trends. Correlations with rf, which are nearly all significantly positive, imply clear process links between rainfall, nitrate leaching and river water concentrations. Correlations with $\mathrm{rf}-1$ are significantly negative for windows ending around 1990, a period when annual rainfall totals were low. Once again, there are no significant correlations for $\mathrm{rf}-2$.

\section{Conclusions}

We draw the following conclusions:

1. The pattern of long-term change revealed for the River Stour reflects the complex interactions between nitrogen availability in the catchment, hydrological controls over nitrate leaching and hydrogeologically controlled delays in solute breakthrough. The decrease in nitrate concentrations appears to have started in the early 1980s, before widespread nitrogen control measures were introduced. This suggests that much of the rising trend in the post-war period was caused by nitrogen mineralisation in soil resulting from ploughing of old grassland (Whitmore et al., 1992) and augmented by increased nitrogen inputs.

2. Climatic fluctuations induce high-frequency variations around the long-term trend. Rainfall in the current year is significantly and positively correlated with nitrate concentration, as would be expected; this is seen for 10-year windows and longer. The "memory effect" is seen to shift from negative to positive in the 10-year window. This could either relate to a shift from drier to wetter years, or indicate the progressive intensification of farming. Either way, the system seems to have moved from supply-limited conditions (in which the overall trend appears to have been influenced predominantly by nitrogen availability in the system) to a transportlimited state (in which nitrogen availability is relatively constant and temporal variations in concentrations are controlled mainly by hydrological conditions). Both the timing and the shift mirror results found elsewhere (Burt and Worrall, 2007). Only the negative memory effect is significant when longer windows are considered. Here, no significant lags are identified for $\mathrm{rf}-2$.

3. Use of moving window analysis has shown that statistically significant trends may be identified for almost any time period. However, this study suggests that the response times for nitrate in this system can be of the order of 20-30 years (particularly in the case of reequilibration of soil organic matter levels in ploughedout pasture: Whitmore et al., 1992). Management decisions made on shorter data sets (even up to 15 years) could, therefore, be misleading: interventions could 
be judged unsuccessful, even if they have had significant positive impact in the long term. However, as Fig. 2 shows, generally, long-term trends are beginning to emerge after a decade.

4. There are three implications for scientists and government agencies involved in environmental policy and management. First, in order to know if change is happening, monitoring systems must be adequately maintained over long periods - records less than thirty years may well be of little use (Burt, 1994). Secondly, when results are analysed, they must be viewed within an appropriate historical context (i.e. a sufficiently long record) in order to be able to distinguish the impact of policy-driven change from shorter-term variability. Thirdly, present nitrate management strategies have not taken into account the evidence that the impact of such strategies will always have a limited effect within the context of major land-use change (i.e. widespread ploughing of grassland in the post-war period). Further work is required to identify both appropriate timescales over which prediction could be reliable, and the extent to which such temporal patterns are consistent between catchments and basins.

The exceptional length of the nitrate record for the River Stour and the use of varying window width have allowed us to understand the time constants of the system and contextualise management strategies. There are few such long nitrate time series for UK rivers and so these data provide a rare opportunity to undertake such analyses. The maintenance of long-term records for representative river basins is crucial to assess present and future policy decisions. Changes in sampling frequency, such as that implemented in 2001 (i.e. a reduction from weekly to monthly sampling) are to be regretted because they undermine the quality of the record. But other arguments may also be needed to persuade agencies to even maintain monitoring networks and sampling frequencies, let alone extend them. These include identification of the longterm consequences of major drivers like climate change, particularly where such change may be harmful to ecosystems, the validation of simulation models, and the testing of hypotheses undreamt of at the time the monitoring network was set up (Burt, 1994).

Acknowledgements. We are grateful to two anonymous referees for their very helpful comments on the "Discussion" version of this paper, to the Environment Agency for supplying data, and to all those responsible for taking water samples from the Stour at Langham.

Edited by: G. Pinay

\section{References}

ADAS: Nitrates in water - the current status in England (2006): Consultation report D1 to the UK Department of Environment, Food and Rural Affairs, available online: http://www.defra.gov.uk/environment/water/quality/nitrate/ pdf/consultation-supportdocs/d1-nitrateswater.pdf, 2007.

Betton, C., Webb, B. W., and Walling, D. E.: Recent trends in $\mathrm{NO}_{3}$ $\mathrm{N}$ concentrations and loads in British rivers, Int. Assoc. Hydrol. Sci. Pub., 203, 169-180, 1991.

Burt, T. P.: Long-term study of the natural environment: perceptive science or mindless monitoring?, Prog. Phys. Geog., 18, 475496, 1994.

Burt, T. P. and Horton, B. P.: Inter-decadal variability in daily rainfall at Durham (UK) since the 1850s, Int. J. Climatol., 27, 945956, doi:10.1002/joc.1443, 2007.

Burt, T. P. and Johnes, P. J.: Managing water quality in agricultural catchments, T. I. Brit. Geogr, NS22(1), 61-68, 1997.

Burt, T. P. and Worrall, F.: Non-stationarity in long time series: some curious reversals in the 'memory' effect, Hydrol. Process., 21, 3529-3531, 2007.

Burt, T. P., Arkell, B. P., Trudgill, S. T., and Walling, D. E.: Stream nitrate levels in a small catchment in south west England over a period of 15 years, Hydrol. Process., 2, 267-284, 1988.

Burt, T. P., Heathwaite, A. L., and Trudgill, S. T.: Nitrate: Processes, Patterns and Management, John Wiley, Chichester, 1993.

Casey, H. and Clarke, R. T.: Statistical analysis of nitrate concentrations from the river Frome (Dorset) for the period 1965-76, Freshwater Biol., 9, 91-97, 1979.

Casey, H., Clarke, R. T., and Smith, S. M.: Increases in nitrate concentrations in the River Frome (Dorset) Catchment related to changes in land use, fertiliser applications and sewage input, Chem. Ecol., 8, 105-117, 1993.

Dixon, H., Lawler, D. M., and Shamseldin, A. Y.: Streamflow trends in western Britain, Geophys. Res. Lett., 33, L19406, doi:10.1029/2006GL027325, 2006.

Doornkamp, J. C., Gregory, K. J., and Burn, A. S. (Eds.): Atlas of Drought in Britain 1975-76, London, Institute of British Geographers, 1978.

Hunt, D. T. E., Dee, A. S., and Oakes, D. B.: Updating the estimates of the source apportionment of $\mathrm{N}$ to UK waters. Phase 2. DEFRA report by WRc plc., available online: http://www.fwr. org/defrawqd/wqd0002.htm, 2004.

Johnston, R. J.: Multivariate Statistical Analysis in Geography, Longman, London, 1978.

José, P.: Long-term nitrate trends in the River Trent and four main tributaries, Regul. Rivers, 4, 43-57, 1989.

Kirchner, J. W., Feng, X., and Neal, C.: Fractal stream chemistry and its implications for contaminant transport in catchments, Nature 403, 524-527, 2000.

National River Flow Archive (NRFA): Centre for Ecology and Hydrology, Wallingford, UK, available online: http://www.ceh.ac. uk/data/nrfa/index.html, last acceess: 7 November 2008.

National River Flow Archive (NRFA): Catchment Land Use Map for the Stour at Langham Bridge, Centre for Ecology and Hydrology, UK, available online: http://www.nwl.ac.uk/ih/nrfa/ spatialinfo/LandUse/landuse036006.html, 2008.

Owens, L. B. and Edwards, W. M.: Long-term groundwater quality changes from a one-time surface bromide application, J. Environ. Qual., 21, 406-410, 1992. 
Royal Society: The Nitrogen Cycle of the United Kingdom, Royal Society, London, 1983.

Roberts, G. and Marsh, T.: The effects of agricultural practices on the nitrate concentrations in the surface water domestic supply sources of Western Europe, International Association of Hydrological Sciences Publication, 164, 365-380, 1987.

Stuart, M. E., Chilton, P. J., Kinniburgh, D. G., and Cooper, D. M.: Screening for long-term trends in groundwater nitrate monitoring data, Q. J. Eng. Geol. Hydroge., 40, 361-376, 2007.

The Mathworks: www.mathworks.com, 2007, last access: 7 November 2008.
Whitmore, A. P., Bradbury, N. J., and Johnson, P. A.: Potential contribution of ploughed grassland to nitrate leaching, Agr. Ecosyst. Environ., 39, 221-233, 1992.

Worrall, F. and Burt, T. P.: A univariate model of river water nitrate time series, J. Hydrol., 214, 74-90, 1999.

Worrall, F., Swank, W. T., and Burt, T. P.: Changes in nitrate export due to ecological succession, land management and climate: developing a systems approach to integrated catchment response, Water Resour. Res., 39, 7, 1-14, 2003. 